\title{
SINGLE-PHASE ACTIVE POWER FILTERS WITH REDUCED NUMBER OF POWER SWITCHES AND OPTIMUM VOLTAGE CONTROL ANGLE
}

\begin{abstract}
This paper proposes some topologies of universal active power filter for single-phase applications with reduced number of components. Some configurations are proposed: two with both series and parallel converters connected in half-bridge, sharing the same d.c.-bus mid-point connection; and the others with the series and parallel converters sharing one leg. It will be demonstrated the existence of a coupling law between the two converters $\left(S_{e}\right.$ and $\left.S_{h}\right)$ related to the voltage capabilities. All configurations compensate for current and voltage harmonic and provide power factor control close to one. Comparisons between the structures are made and the steady-state analysis are also presented to demonstrate that it is possible to obtain an optimum voltage angle in order to reduce the amplitudes of the converters' currents and, consequently, the total losses of the systems. Simulated and experimental results validate the theoretical considerations.
\end{abstract}

Welflen R. N. Santos, Edison R. C. da Silva ${ }^{\dagger}$, Cursino B. Jacobina ${ }^{\dagger}$, Eisenhawer de M. Fernandes ${ }^{\dagger}$, Alexandre C. Oliveira ${ }^{\dagger}$, Rafael R. Matias, Dalton F. G. Filho ${ }^{\diamond}$, Otacilio M. Almeida, Patryckson M. Santos ${ }^{\star}$

Federal University of Piauí, ${ }^{\dagger}$ Federal University of Campina Grande, ${ }^{\diamond} \mathrm{CHESF},{ }^{\star}$ Federal University of Maranhão

\section{e-mail: welflen@ufpi.edu.br}

Keywords - Active Power Filter, Optimum Voltage Angle, Reduced Number of Components, Two-leg Converter.

\section{INTRODUCTION}

The continuous proliferation of electronic equipment either for home appliances or industrials uses have the drawback of increasing the non-sinusoidal current into power network. Different mitigation solutions are currently proposed and used in practical applications to work out the problems of harmonics in electric grids. In the last decades, the use of active filtering techniques has became more attractive due to the technological progress in power electronic switching devices, enhanced numerical methods and more efficient control algorithms.

The Series Active Power Filter (SAPF) [1], [2], [3] provides load voltage control, eliminating voltage disturbances, such as unbalance, sags, notches, flickers and voltage harmonics, so that a regulated fundamental load voltage with constant magnitude is provided to the load. The purpose of a Parallel Active Power Filter (PAPF) also knowing as shunt, [4], [5], [6], [7], [8] is to absorb harmonics current, compensate for reactive power and regulate the d.c.-bus voltage. The Universal Active Power Filter (UAPF) [9], [10], [11], [12] [13], [14], which is combination of both ones, is a versatile device that operates as series and parallel active power filter. Then, it can simultaneously fulfill different objectives like

Manuscript received in $17 / 03 / 2013$. First revision in $16 / 07 / 2013$, second revision in $25 / 09 / 2013$. Accepted for publication in $25 / 09 / 2013$, by recommendation of the Editor Henrique A. C. Braga. maintaining a balanced sinusoidal (harmonic free) nominal voltage at the load bus, source current harmonics elimination, load balance and power factor correction.

UAPF is appeared to be a strong tool to improve power quality in many applications and it has been attracting the attention of many researchers in order to reduce cost, size and weight. Generally, the largest cost reduction is achieved by reducing the number of switches employed in a converter power circuit or developing topologies that employ switches with lower voltage stresses [15], [16], [17], [18], [19]. In this field, the challenge is to choice between full-bridge and half-bridge topologies. The main attributes for the sake of comparison are: the number of bi-directional switches (two for the half-bridge and four for the full-bridge); the voltages of the switches (rated line voltage for the full-bridge and half of the rated line voltage for the half-bridge) and capacitor current in the case of the half-bridge.

A conventional UAPF topology, Figure 1, consists of two full-bridge bi-directional converters connected to a common d.c.-bus. The series bi-directional converter consists of four

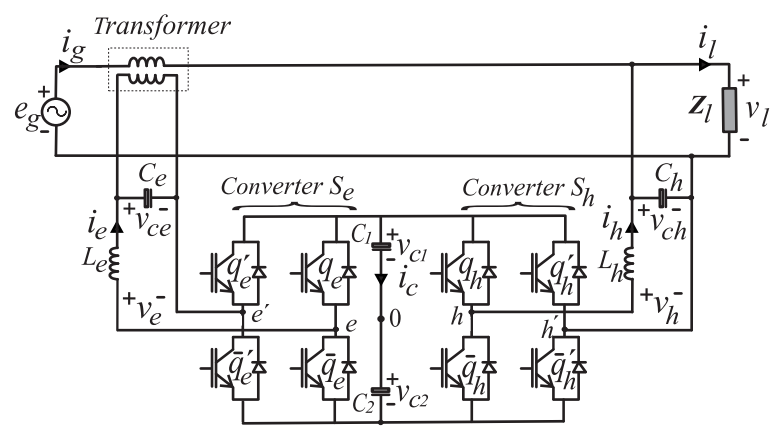

Fig. 1. Conventional topology of single-phase Universal Active Power Filter (UAPF).

switches connected via transformer in series with the a.c line. The parallel bi-directional converter also consists of four switches. As the number of electronic power switches is reduced to achieve low cost and high performance at the same time the d.c.-bus voltage must increase. For the controllability of the conventional UAPF system, the voltage of the d.c-bus must be $\frac{3}{2}$ times of the peak voltage of the a.c. line. In configurations with two-leg converters, the voltage of both capacitors $C_{1}$ and $C_{2}$ must be $\frac{3}{2}$ times of the peak voltage of the line voltage. Therefore, the voltage of the capacitor bank must be three times of the a.c. line peak voltage [11], [18].

This paper proposes some configurations of UAPF with reduced number of components for single-phase applications. Configurations have only two-leg and use a capacitor bank with d.c.-bus mid-point connection. In Figure 2 are presented 
some conventional structures of UAPF with transformer connected in series side. The configurations presented in Figure 3 are directly connected to the distribution system without a series injection transformer, the transformer is used in parallel to the load [20]. This configurations may be feasible when the transformer turns ratio $n$, of the transformer winding connected to the parallel converter, is varied in order to reduce the d.c.-bus voltage. The operation principle, control strategy, steady-state analysis and experimental results are presented to validate the theoretical considerations.

\section{FREQUENCY MODULATION}

Configurations presented in Figure 2 have a transformer in the series side connection and the presented in Figure 3 are connected to the distribution system without series injection transformer, which may struggles with core saturation and voltage drop [21]. However, the magnetic flux in iron core of series transformer may change in a large range depending on the close angle of injecting voltage, at the same time iron core easily get over saturated. Over saturation in transformer iron core leads to produce large field inrush current and distortion on compensating voltage waveform [22]. These configurations use the transformer in parallel to the load.

The active power filters configurations for single-phase applications can be composed by two-leg converters [23]. They can be classified into $2 L, 2 L_{e}$ and $2 L_{h}$. The converters, Figure 2 and 3 , can operate both sides in half-bridge (denoted as $2 L$ configurations) or one side in full-bridge and the other one in half-bridge with a shared-leg (denoted as $2 L_{e}$ and $2 L_{h}$ configurations). In $2 L_{e}$ the shared-leg is $h$ and for $2 L_{h}$ is the leg $e$.

The configurations $2 L_{e}$ and $2 L_{h}$ can operate in halfbridge and full-bridge, but there is a coupling law between the two converters. Half-bridge converters voltages are limited by $v_{e}<\left(\frac{E}{2}\right)$ (topologies $2 L_{h}$ ) and $v_{h}<\left(\frac{E}{2}\right)$ (topologies $2 L_{e}$ ). Full-bridge converters voltages are limited by $v_{h}<E$ (topologies $2 L_{h}$ ) and $v_{e}<E$ (topologies $2 L_{e}$ ). Both converters in half-bridge (topologies $2 L$ ) are connected to a common d.c.-bus mid-point connection and have the converters voltages limited by $v_{e}=\left(\frac{E}{2}\right)$ and $v_{h}=\left(\frac{E}{2}\right)$, being $E=v_{c}=v_{c 1}+v_{c 2}$.

The conduction state of the switch-pairs is represented by homonymous binary variables $q_{e}, \bar{q}_{e}, q_{h}$ and $\bar{q}_{h}$, where $q=1$ indicates a closed switch while $q=0$ indicates an open one. The pair of switches $q_{e}$ or $\bar{q}_{e}$ and $q_{h}$ or $\bar{q}_{h}$ are complementary, so

$$
\begin{aligned}
q_{e} & =1-\bar{q}_{e} \\
q_{h} & =1-\bar{q}_{h}
\end{aligned}
$$

The pulse-widths of the gating signals are determined from the reference pole voltages $v_{e 0}^{*}$ and $v_{h 0}^{*}$, as noted in

$$
\begin{aligned}
\tau_{e} & =\frac{T}{2}+\frac{T}{E} v_{e 0}^{*} \\
\tau_{h} & =\frac{T}{2}+\frac{T}{E} v_{h 0}^{*}
\end{aligned}
$$

where $T$ is the sample period for the pulse-width modulation (PWM). The reference signals for the pole voltages $v_{e 0}^{*}$ and

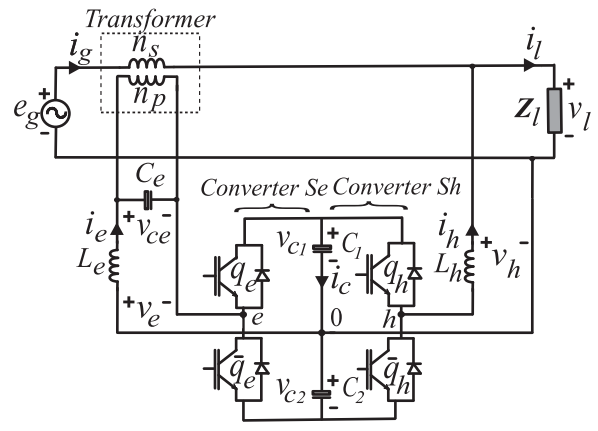

(a)

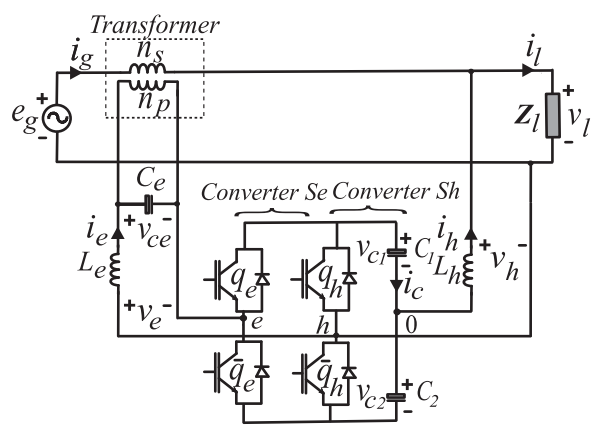

(b)

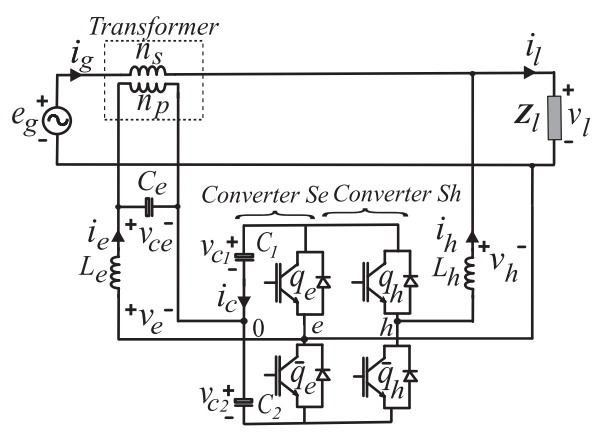

(c)

Fig. 2. Single-phase UAPF with transformer in series connection configurations: (a) $2 L$ (b) $2 L_{e}$ and (c) $2 L_{h}$.

$v_{h 0}^{*}$ are determined from the reference voltages $v_{e}^{*}$ and $v_{h}^{*}$. The reference signals to the pole voltages of the UAPF converters are presented in the next subsections.

\section{A. Configuration $2 L$}

Configurations $2 L$ have both the converters in half-bridge topologies. Voltages $v_{e}$ and $v_{h}$ are in function of the converter pole voltages $v_{e 0}$ and $v_{h 0}$ which depend on the conduction states of the power switches and individual voltage of the capacitors $v_{c 1}$ and $v_{c 2}$, then:

$$
\begin{gathered}
v_{e}=v_{e 0}=q_{e} v_{c 1}-\left(1-q_{e}\right) v_{c 2} \\
v_{h}=v_{h 0}=q_{h} v_{c 1}-\left(1-q_{h}\right) v_{c 2}
\end{gathered}
$$

where $v_{c 1}$ and $v_{c 2}$ denote the capacitors voltages. The reference pole voltages can be expressed by:

$$
\begin{aligned}
& v_{e 0}^{*}=v_{e}^{*} \\
& v_{h 0}^{*}=v_{h}^{*}
\end{aligned}
$$




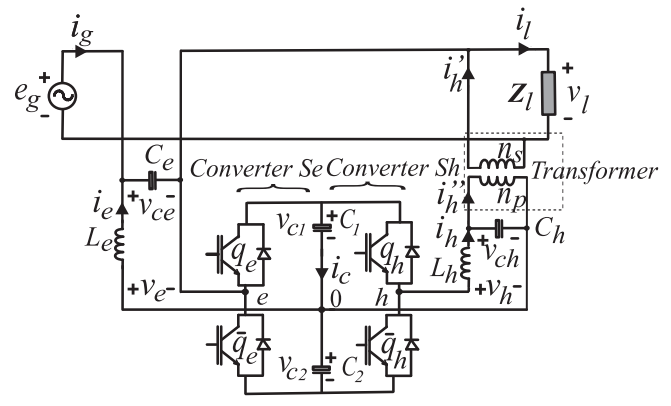

(a)

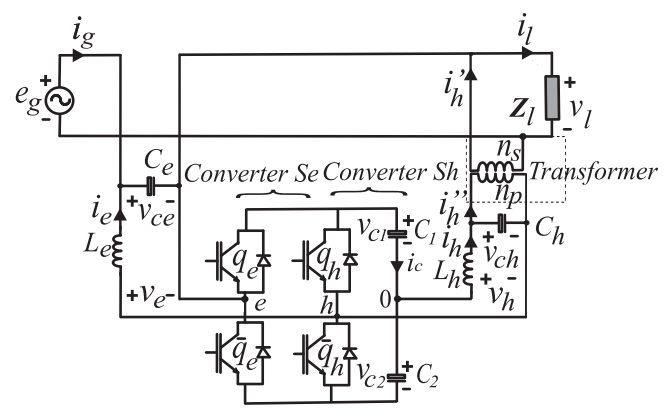

(b)

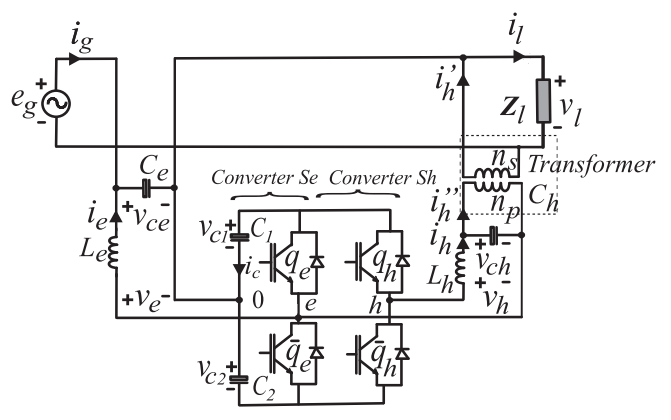

(c)

Fig. 3. Single-phase UAPF with transformer in parallel side configurations: (a) $2 L$ (b) $2 L_{e}$ and (c) $2 L_{h}$.

\section{B. Configuration $2 L_{e}$}

Configurations $2 L_{e}$ have the converter $S_{e}$ in full-bridge and $S_{h}$ in half-bride. Voltages $v_{e}$ and $v_{h}$ can be expressed as a function of the converter pole voltages $v_{e 0}$ and $v_{h 0}$ that depend on the conduction states of the power devices, so:

$$
\begin{array}{r}
v_{e}=v_{e 0}-v_{h 0}=\left(q_{e}-q_{h}\right) E \\
v_{h}=v_{h 0}=q_{h} v_{c 1}-\left(1-q_{h}\right) v_{c 2}
\end{array}
$$

It can be noted that the voltage $v_{e}$ does not depend on the individual capacitors voltages $v_{c 1}$ and $v_{c 2}$.

Considering that $v_{e}^{*}$ and $v_{h}^{*}$ denote the desired reference voltages, then the reference pole voltages can be expressed by:

$$
\begin{array}{r}
v_{e 0}^{*}=v_{e}^{*}+v_{h}^{*} \\
v_{h 0}^{*}=v_{h}^{*}
\end{array}
$$

Defining the reference pole voltages, pulse-widths $\tau_{e}$ and $\tau_{h}$ can be generated from (3) and (4).

\section{Configuration $2 L_{h}$}

Configurations $2 L_{h}$ have the converter $S_{h}$ in full-bridge and $S_{e}$ in half-bride. Voltages $v_{e}$ and $v_{h}$ can also be expressed as a function of the converter pole voltages $v_{e 0}$ and $v_{h 0}$, so:

$$
\begin{gathered}
v_{e}=v_{e 0}=q_{e} v_{c 1}-\left(1-q_{e}\right) v_{c 2} \\
v_{h}=v_{h 0}-v_{e 0}=\left(q_{h}-q_{e}\right) E
\end{gathered}
$$

In this case, the voltage $v_{e}$ does not depend on the individual capacitor voltages $v_{c 1}$ and $v_{c 2}$. The reference pole voltages can be expressed as:

$$
\begin{array}{r}
v_{e 0}^{*}=v_{e}^{*} \\
v_{h 0}^{*}=v_{h}^{*}+v_{e}^{*}
\end{array}
$$

Then, the pulse-widths can be calculated by using (3) and (4).

\section{SHARED-LEG AND CAPACITOR CURRENTS}

The currents flowing through the shared-leg, for configurations $2 L_{e}$ and $2 L_{h}$, and capacitor current for $2 L$ depend on the currents $i_{e}$ and $i_{h}$. The description of shared-leg and capacitor current are presented in the next subsections.

\section{A. Configuration $2 L$}

Neglecting the frequency $2 \omega$ due to the single-phase power flow [24]. The capacitors average currents for configurations $2 L$ are given by:

$$
\begin{aligned}
\bar{\imath}_{c 1} & =\frac{\bar{\imath}_{e}-\bar{\imath}_{h}}{2} \\
\bar{\imath}_{c 2} & =\frac{\bar{\imath}_{h}-\bar{\imath}_{e}}{2}
\end{aligned}
$$

\section{B. Configuration $2 L_{e}$}

In these configurations the shared-leg is $h$ between converters $S_{e}$ and $S_{h}$. Currents flow through the top and down switches $q_{h}$ and $\overline{q_{h}}$ are:

- for $q_{h}=1$ (during $\tau_{h}$ ):

$$
\begin{array}{r}
i_{q h}=\left(i_{e}+i_{h}\right) \\
\imath_{\bar{q} h}=0
\end{array}
$$

- for $q_{h}=0$ (during $\left.T-\tau_{h}\right)$ :

$$
\begin{array}{r}
i_{q h}=0 \\
\imath_{\bar{q} h}=-\left(i_{e}+i_{h}\right)
\end{array}
$$

The equations can be rewritten as follows:

$$
\begin{array}{r}
i_{q h}=q_{h}\left(i_{e}-i_{h}\right) \\
i_{\bar{q} h}=-\left(1-q_{h}\right)\left(i_{e}-i_{h}\right)
\end{array}
$$

It is possible to determine the average value of the current $i_{q h}$ and $i_{\bar{q} h}$ within the period $T$ :

$$
\begin{aligned}
\bar{\imath}_{q h} & =\frac{1}{T} \int_{\tau} i_{q h} d t \\
\bar{\imath}_{\bar{q} h} & =\frac{1}{T} \int_{\tau} i_{\bar{q} h} d t
\end{aligned}
$$


Neglecting the high-frequency current components due to the switching and assuming that the interval $T$ is too small, the average current flowing through each switch $q_{h}$ and $\overline{q_{h}}$ of the shared-leg are given by:

$$
\begin{aligned}
\bar{\imath}_{q h} & =\frac{\tau}{T}\left(\bar{\imath}_{e}-\bar{\imath}_{h}\right) \\
\bar{\imath}_{\bar{q} h} & =\frac{T-\tau}{T}\left(\bar{\imath}_{e}-\bar{\imath}_{h}\right)
\end{aligned}
$$

Substituting (4) in (27) and (28), the average current flowing through each switches of the shared-leg are given by:

$$
\begin{aligned}
& \bar{\imath}_{q h}=\left(\frac{v_{h 0}^{*}}{E}+\frac{1}{2}\right)\left(\bar{\imath}_{e}-\bar{\imath}_{h}\right) \\
& \bar{\imath}_{\bar{q} h}=\left(\frac{v_{h 0}^{*}}{E}-\frac{1}{2}\right)\left(\bar{\imath}_{e}-\bar{\imath}_{h}\right)
\end{aligned}
$$

Capacitors currents of the dc-link for configurations $2 L_{e}$ are:

$$
\begin{array}{r}
i_{c 1}=q_{e} i_{e}-q_{h}\left(i_{e}-i_{h}\right) \\
i_{c 2}=i_{c 1}-i_{h}
\end{array}
$$

and average currents are given by:

$$
\begin{gathered}
\bar{\imath}_{c 1}=\frac{1}{2} \bar{\imath}_{h} \\
\bar{\imath}_{c 2}=-\frac{1}{2} \bar{\imath}_{h}
\end{gathered}
$$

Ignoring the frequency due to the single-phase power flow.

\section{Configuration $2 L_{h}$}

The procedure to determine the average currents for these configurations is similar to that presented in section III.B. Then, the average current flowing through each switch of the shared-leg $q_{e}$ and $\overline{q_{e}}$ are given by:

$$
\begin{aligned}
& \bar{\imath}_{q e}=-\left(\frac{v_{e 0}^{*}}{E}+\frac{1}{2}\right)\left(\bar{\imath}_{e}-\bar{\imath}_{h}\right) \\
& \bar{\imath}_{\bar{q} e}=-\left(\frac{v_{e 0}^{*}}{E}-\frac{1}{2}\right)\left(\bar{\imath}_{e}-\bar{\imath}_{h}\right)
\end{aligned}
$$

It is also observed that the current in the shared-leg is defined by the sum of currents $i_{e}$ and $i_{h}$.

Capacitor currents of the d.c.-link for these configurations are given by:

$$
\begin{array}{r}
i_{c 1}=-q_{h} i_{h}+q_{e}\left(i_{h}-i_{e}\right) \\
i_{c 2}=i_{c 1}+i_{e}
\end{array}
$$

and average currents are:

$$
\begin{gathered}
\bar{\imath}_{c 1}=-\frac{1}{2} \bar{\imath}_{e} \\
\bar{\imath}_{c 2}=\frac{1}{2} \bar{\imath}_{e}
\end{gathered}
$$

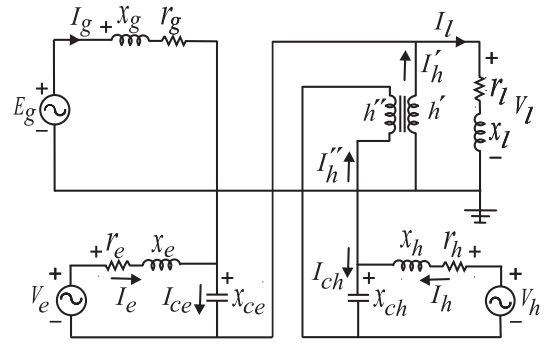

(a)

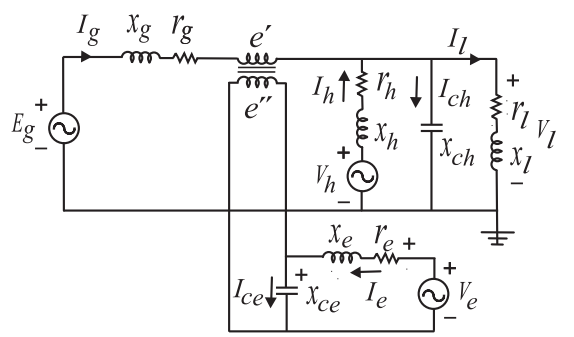

(b)

Fig. 4. Steady-state circuits: (a) transformer in parallel side and (b) transformer in series connection.

\section{STEADY-STATE CHARACTERISTICS}

Steady-state analysis of the presented configurations with the transformer connected in parallel or in series side are based on the model shown, respectively, in Figure 4(a) and 4(b). The figures compromise the grid $\left(E_{g}\right.$ and $\left.I_{g}\right)$, internal grid impedance $\left(r_{g}\right.$ and $\left.x_{g}\right)$, series voltage $\left(V_{e}\right)$, series impedance $\left(r_{e}, x_{e}\right.$ and $\left.x_{c e}\right)$, series current $\left(I_{e}\right)$, parallel voltage $\left(V_{h}\right)$, parallel impedance $\left(r_{h}, x_{h}\right.$ and $\left.x_{c h}\right)$, parallel current $\left(I_{h}\right)$, series and parallel transformers, and load impedance $\left(r_{l}, x_{l}\right)$.

Voltage sources $V_{e}$ and $V_{h}$ represent the converters generated voltages of converters $S_{e}$ and $S_{h}$, respectively. The power load $S_{l}$ presents a inductive power factor $(P F)$ equal to 0.85 . All results presented in this section are in function of load angle $\delta_{l}$. This angle is the phase angle between the grid voltage $e_{g}$ and load voltage $v_{l}$. Otherwise, the values of the parameters are represented in p.u. system.

In Figs. 5 and 6 are shown the results for the proposed UAPF with transformer connected in the parallel side using the following parameters: $\left|e_{g}\right|=1.0,\left|v_{l}\right|=1.0, r_{g}=0.001$, $r_{e}=0.005, r_{h}=0.005, r_{h}^{\prime}=0.003, r_{h}^{\prime \prime}=0.003, x_{g}=0.01$, $x_{e}=0.33, x_{h}^{\prime}=0.33, x_{h}^{\prime \prime}=0.33, x_{m}=0.9, x_{h}=0.33$, $x_{c e}=1.0, x_{c h}=0.5$. The converter voltage amplitudes $V_{e}$ and $V_{h}$ are observed in Figure 5(a).

In this figure, the voltage amplitude of series converter $V_{e}$ assume the lowest value at $\delta_{l} \approx-3.5^{\circ}$. As $\delta_{l}$ moves away from $\delta_{l} \approx-3.5^{\circ}$ the voltage $V_{e}$ increases considerably. It is noted in Figure 5(b) that the converters' currents amplitude $I_{e}$ and $I_{h}$ assume the lowest values, respectively, at $\delta_{l} \approx-40^{\circ}$ and $\delta_{l} \approx 36^{\circ}$, while the amplitude of $I_{g}$ remains practically constant on the $\delta_{l}$ variation. The current $I_{h}^{\prime}$ has the smallest amplitude value at $\delta_{l} \approx 32^{\circ}$.

From Figure 6, it can be seen that the system has better performance for a load angle close to $\delta_{l} \approx-30^{\circ}$. This operating point corresponds to the range in which the 


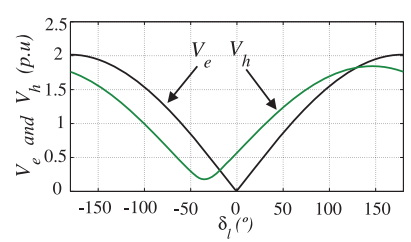

(a)

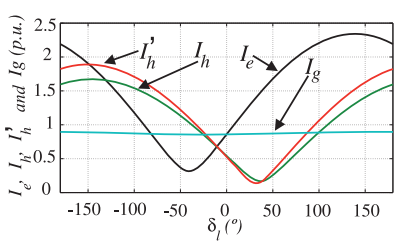

(b)
Fig. 5. Steady-state analysis of single-phase UAPF with transformer in parallel side: (a) converter voltages and (b) converters, transformer and grid currents.

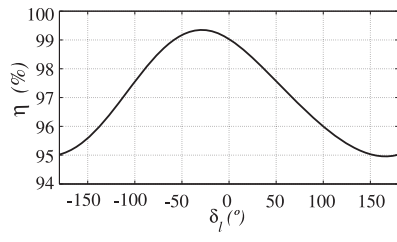

(a)

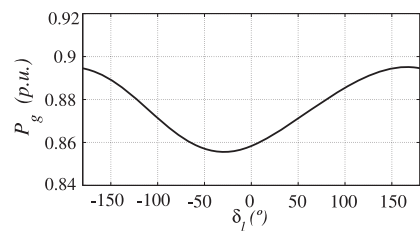

(b)
Fig. 6. Steady-state analysis of single-phase UAPF with transformer in parallel side: (a) efficiency and (b) a.c. power grid.

amplitudes of the converters' current $I_{e}$ and $I_{h}$ are smaller. In Figure $6(b)$ is observed that the point of maximum performance occurs when the power source has the lower amplitude.

In Figs. 7 and 8 are presented the results for the proposed UAPF with transformer connected in the series side, the results were obtained using the following parameters: $\left|e_{g}\right|=1.0$, $\left|v_{l}\right|=1.0, r_{g}=0.001, r_{e}=0.005, r_{h}=0.005, r_{h}^{\prime}=0.003$, $r_{h}^{\prime \prime}=0.003, x_{g}=0.01, x_{e}=0.33, x_{h}^{\prime}=0.33, x_{h}^{\prime \prime}=0.33$, $x_{m}=0.9, x_{h}=0.33, x_{c e}=1.0, x_{c h}=1.0$.

Similar results are presented for the configuration with transformer in series side. The explanations of the presented simulated results are similar to the previous case. The steadystate analysis are shown in Figs. 7 and 8 . Comparing the

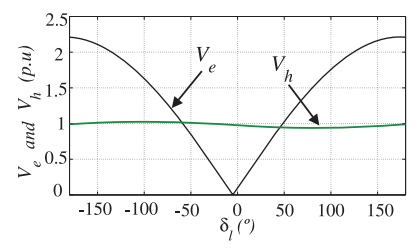

(a)

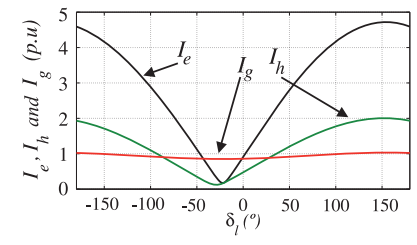

(b)
Fig. 7. Steady-state analysis of the proposed single-phase UAPF with transformer in series connection: (a) converter voltages and (b) converters, transformer and grid currents.

steady-state circuits analysis, it is clearly observed that the configuration with transformer in parallel side also presents the possibility to reduce the d.c.-bus voltage by varying the load angle instead of changing the transformer turns ratio $n=$ $\left(\frac{n_{p}}{n_{s}}\right)$, as the voltage of the parallel converter $V_{h}$ is reduced the capacitor d.c.-bus voltage can also be, see Figure 5(a). There are two options for reducing the d.c.-bus voltage: (1) varying the load angle and (2) changing the transformer turns ratio.

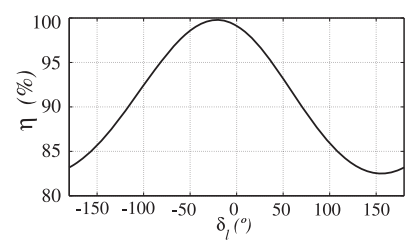

(a)

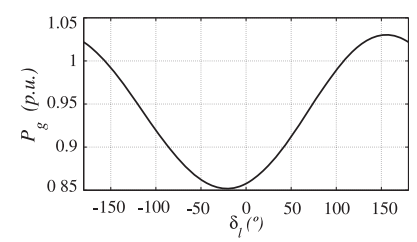

(b)
Fig. 8. Steady-state analysis of single-phase UAPF with transformer in series connection: (a) efficiency and (b) a.c. power grid.

From Figure 6(a) it is noted that the parallel converter voltage $V_{h}$ remains practically constant with changes in the load angle $\delta_{l}$. For both structures, as the currents of the converters are reduced the voltage amplitude of the series converter is increased. To obtain the point of minimum losses is necessary to have available d.c.-bus voltage at the capacitors. The voltage of the series converter $\left(V_{e}\right)$ drastically increase as the load angle is varied, Figs. 5(a) and 7(a), then, the d.c.-bus capacitors needs to supply more energy for the series converter in order to provide the correct voltage compensation.

\section{CONTROL STRATEGY}

The block diagram of the proposed configurations can be seen in Figure 9. The d.c.-bus voltage is compared with the

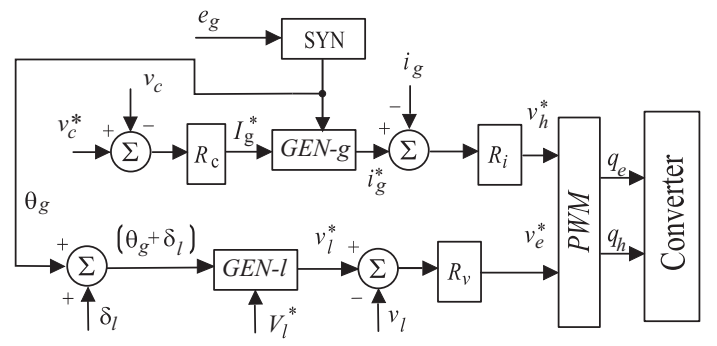

Fig. 9. Control block diagram for the proposed Universal Active Power Filter (UAPF).

reference voltage $v_{c}^{*}$ and the error is applied to the input of a PI controller $R_{c}$.

The output of $R_{c}$ controller defines the current amplitude of reference signal $I_{g}^{*}$ that is synchronized with the grid voltage $e_{g}$ in order to control the power factor, this is done via block $G E N-g$. This block defines the current $i_{g}^{*}$. This synchronism is accomplished by PLL (Phase Locked Loop) to produce the reference voltage. The input of the $P L L$ is the grid voltage. The output of the $P L L$ is a $60 H z$ reference voltage, which is exactly in phase with the grid voltage. The current error $\left(i_{g}^{*}-i_{g}\right)$ is applied to current controller represented by $R_{i}$. The controller $R_{i}$ is a double sequence digital current controller [25]. The output voltage $v_{h}$, of this controller, is used to determine the switches conduction state.

The voltage regulation applied to the load is determined from the instantaneous reference load voltage $v_{l}^{*}$ which is obtained by the voltage amplitude $V_{l}^{*}$ and by the angles $\theta_{g}$ and $\delta_{l}$ via block $G E N-l . \theta_{g}$ is the instantaneous angle of $e_{g}$ and $\delta_{l}$ is used to determine the best operating point of the system. This information is applied to the block $R_{v}$ which is also a 
modified $P I$ controller similar to presented $R_{i}$ controller. The output of this controller generates the reference voltage for determining the $P W M$.

\section{EXPERIMENTAL RESULTS}

Some topologies of UAPF, based on two bi-directional converters composed by two-leg connected to a common d.c.link, have been proposed. The topology presented in Figure 3(c) was chosen to compose the experimental result because d.c.-bus voltage can be drastically reduced from the regulation of the transformer turn ratio $n$ and/or the optimized load angle $\delta_{l}$. The proposed single-phase UAPF system presented in Figure 3(c) has been tested by using a microcomputer-based system which is equipped with dedicated boards, in order to generate the control signals. The system have twelve sensors (six current and six voltage sensors), interface card and data acquisition boards, and two static converters each one with three-leg, see Figure 10. In experimental tests, d.c. capacitors

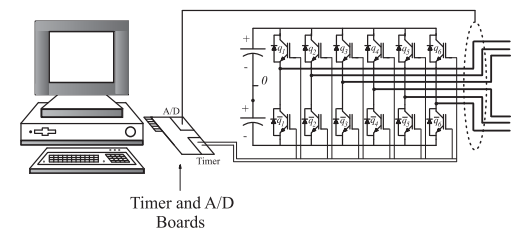

(a)

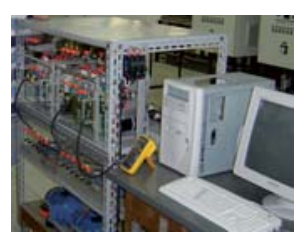

(b)
Fig. 10. Experimental platform in laboratory:(a) Schematic diagram of the converter via PC-based control, (b) Picture of the topology.

were selected as $C=2200 u \mathrm{~F}$, and the switching frequency was set at $10 \mathrm{kHz}$. The system parameters are given by

- Source frequency: $60 \mathrm{~Hz}$;

- Harmonic frequency: $180 \mathrm{~Hz}$;

- d.c.-bus voltage: $380 V_{c c}$ [see Figure 11(c)] and $80 V_{c c}$ [see Figure 13(c)];

- Inductors filters: $5 \mathrm{mH}$;

- Capacitor filter: $70 \mu \mathrm{F}$;

- Nonlinear load composed by diode bridge rectifier with $R=10 \Omega$ and $L=62 \mathrm{mH}$;

- Transformer turn ratio: $n=1$ and $\delta_{l}=0$ for Figure 11 and $n=2$ and $\delta_{l} \approx-30^{\circ}$ for Figure 13 .

The parallel converter requires more energy for compensating harmonics current, provide power factor control close to unit and regulate the d.c.-bus voltage between both converters at desired level; the configurations $2 L_{e}$, due to the shared-leg, need more d.c.-bus voltage compared to the others. According to the steady-state analysis, section $\mathrm{IV}$, all configurations with transformer in parallel side allow to reduce the d.c.-bus voltage varying the load angle and/or the transformer turns ratio. The configurations $2 L_{h}$ with transformer in parallel side was chosen because it requires less d.c.-bus voltage compared to the transformer in series side, and also by the capacitor current for $2 L$ be greater compared to $2 L_{e}$ or $2 L_{h}$.

In the test, the load is supplied by a voltage source generator with $20 \%$ the $3 r d$ harmonic. In Figure 11(a), it is noted that the grid current is compensated with the power factor control

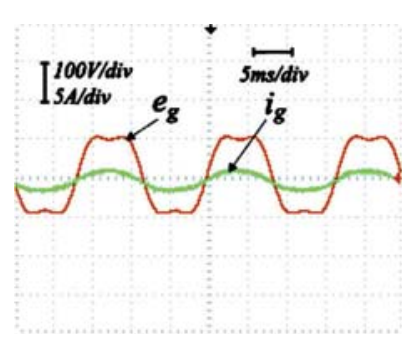

(a)

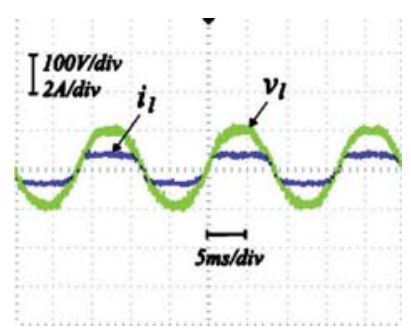

(b)

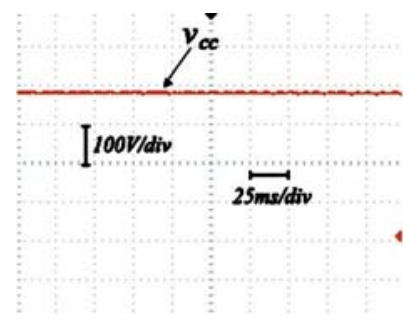

(c)

Fig. 11. Experimental results for proposed UAPF (Configuration $2 L_{h}$ ) with load angle $\delta_{l}=0^{\circ}$ and $n=1$ : (a) grid voltage and current - $e_{g}, i_{g}$, (b) load voltage and current - $v_{l}, i_{l}$, (c) d.c-bus voltage - $v_{c c}$.

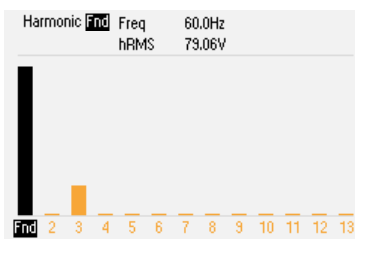

(a)

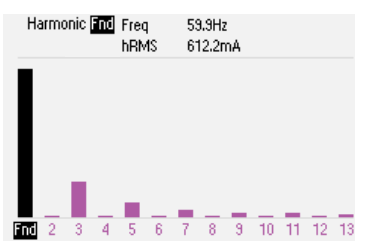

(c)

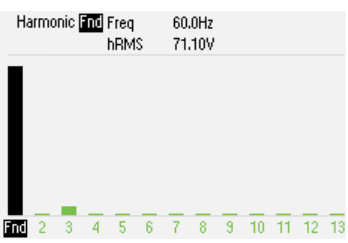

(b)

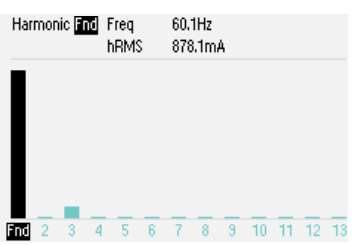

(d)
Fig. 12. Spectral analysis UAPF for proposed UAPF (Configuration $2 L_{h}$ ): (a) grid voltage $e_{g}$, (b)load voltage $v_{l}$, (c) load current $i_{l}$, (d) grid current $i_{g}$.

closed to one and THD (Total Harmonic Distortion) of the current equal to $4.69 \%$. The load presents nonlinear current characteristics with current THD equal to $29.74 \%$ and the load voltage is compensated with THD equal to $3.37 \%$, Figure 11(b). The d.c.-bus voltage is observed in Figure 11(c). The spectral analysis of voltages and currents in the grid and load are also presented in Figure 12.

The set of experimental results presented in Figs. 13 and 14 were obtained considering the transformer turn ratio $n=2$ and load angle $\delta_{l} \approx-30^{\circ}$. The great contribution is related to the drastically reduction of the capacitor voltage in order to obtain the desirable results. The load voltage and grid current are also compensated, with power factor control close to one. The grid current THD is $4.36 \%$, while the load current presents THD equal to $28.74 \%$. The load voltage presents 


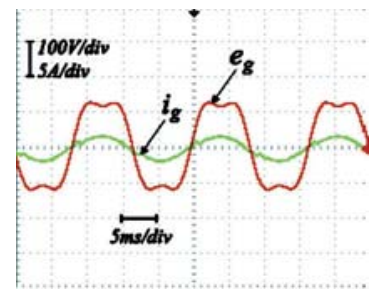

(a)

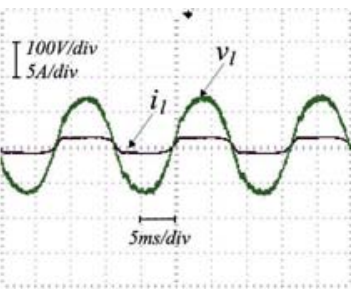

(b)

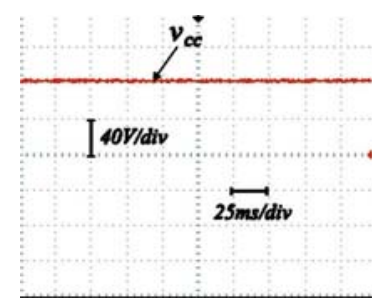

(c)

Fig. 13. Experimental results for proposed UAPF (Configuration $2 L_{h}$ ) with load angle $\delta_{l} \approx-30^{\circ}$ and $n=2$ : (a) grid voltage and current - $e_{g}, i_{g}$, (b) load voltage and current - $v_{l}, i_{l}$, (c) d.c-bus voltage $-v_{c c}$.

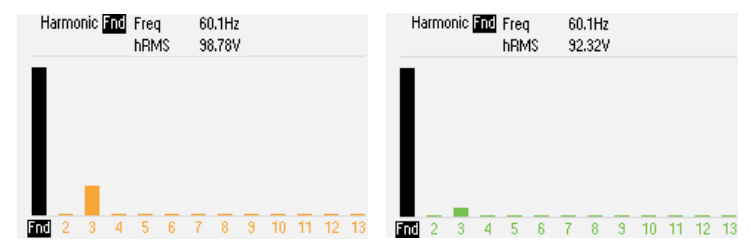

(a)
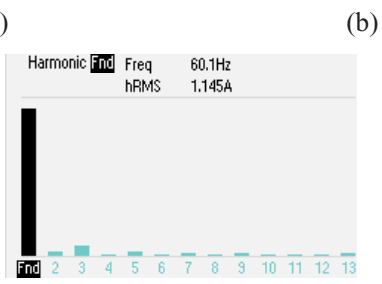

(c)

Fig. 14. Spectral analysis for proposed UAPF (Configuration $2 L_{h}$ ): (a) grid voltage $e_{g}$, (b)load voltage $v_{l}$, (c) grid current $i_{l}$.

THD, for this case, equal to $2.98 \%$.

It can be noted that despite of the distortion on the grid voltages, the load voltages present very low harmonic level, indicating that the filter operates properly.

\section{CONCLUSION}

Some topologies of single-phase active power filter with isolation transformer in the series or parallel side for voltage and current harmonic compensation and power factor control have been presented in this paper. Such analysis showed that it is possible to operate with a load active voltage amplitude regulated at the rated reference value for some grid voltages and load conditions. The grid current compensation is also achieved with power factor control close to one. It was also observed that the capacitors average current for configurations denoted as $2 L$ is higher than $2 L_{e}$ or $2 L_{h}$, but the total losses for $2 L_{e}$ or $2 L_{h}$ are greater than $2 L$ - due to shared-leg current. Comparisons of steady-state analysis were presented and it was noted that the currents of the converters can be reduced from the load angle $\delta_{l}$. Besides, the structures with the transformer in parallel to the load present the option to reduce the capacitors size and d.c.-bus voltages by varying the transformer turn ratio $n$ and/or load angle $\delta_{l}$.

The operation principle, control strategy, steady-state analysis, simulated and experimental results of the proposed single-phase active power filters with reduced number of power switches were presented under different conditions and demonstrated adequate harmonic correction and power factor close to one.

\section{ACKNOWLEDGEMENT}

The authors would like to thank the CAPES (Coordenação de Aperfeiçoamento de Pessoal de Nível Superior) of Brazil for the financial support.

\section{REFERENCES}

[1] J. Perez, V. Cardenas, F. Pazos, and S. Ramirez. Voltage harmonic cancellation in single-phase systems using a series active filter with a low-order controller. In Power Electronics Congress, 2002. Technical Proceedings. CIEP 2002. VIII IEEE International, 2002.

[2] E. R. Ribeiro and I. Barbi. Harmonic voltage reduction using a series active filter under different load conditions. Power Electronics, IEEE Transactions on, 21(5):13941402, september 2006.

[3] S. Inoue, T. Shimizu, and K. Wada. Control methods and compensation characteristics of a series active filter for a neutral conductor. Industrial Electronics, IEEE Transactions on, 54(1):433 -440, feb. 2007.

[4] F. L. Lirio and H. A. C. Braga M. do C. B. Rodrigues. Análise e modelagem do filtro ativo de potência pwm monofásico. Eletrônica de Potência - SOBRAEP 2001, 6(1):25-32, december 2001.

[5] R. Costa-Castelló, R. Grino, and E. Fossas. Oddharmonic digital repetitive control of a single-phase current active filter. Power Electronics, IEEE Transactions on, 19(4):1060-1068, july 2004.

[6] R. F. de Camargo, H. A. Gründling, and H. Pinheiro. Filtro ativo de potência para compensação de harmônicos de tensão em sistemas de distribuição trifásicos a quatro fios. Eletrônica de Potência - SOBRAEP 2007, 12(1):6370, march 2007.

[7] A. Bhattacharya, C. Chakraborty, and S. Bhattacharya. Shunt compensation. Industrial Electronics Magazine, IEEE, 3(3):38 -49, september 2009.

[8] H. Fujita. A single-phase active filter using an h-bridge pwm converter with a sampling frequency quadruple of the switching frequency. Power Electronics, IEEE Transactions on, 24(4):934-941, april 2009.

[9] H. Fujita and H. Akagi. The unified power quality conditioner: the integration of series and shunt-active filters. IEEE Trans. Power Electron., 13(2):315-322, march 1998.

[10] J. Prieto, P. Salmeron, J.R. Vazquez, and J. Alcantara. A 
series-parallel configuration of active power filters for var and harmonic compensation. In IECON 02, volume 4, pages 2945-2950, november 2002.

[11] A. Nasiri and A. Emadi. Different topologies for singlephase unified power quality conditioners. In Industry Applications Conference, 2003., volume 2, pages 976 981 vol.2, octuber 2003.

[12] E. C. dos Santos, C. B. Jacobina, J. A. A. Dias, and N. Rocha. Single-phase to three-phase universal active power filter. Power Delivery, IEEE Transactions on, 26(99):1, 2011.

[13] H. Carneiro, J.G. Pinto, and J.L. Afonso. Singlephase series active conditioner for the compensation of voltage harmonics, sags, swell and flicker. In Industrial Electronics (ISIE), 2011 IEEE International Symposium on, pages $384-389$, june 2011.

[14] V. Khadkikar, A. Chandra, A.O. Barry, and T.D. Nguyen. Power quality enhancement utilising single-phase unified power quality conditioner: digital signal processorbased experimental validation. Power Electronics, IET, 4(3):323 -331, march 2011.

[15] W.-J. Ho, M.-S. Lin, and W.-S. Feng. Common-neutraltype ac/dc/ac topologies with pfc pre-regulator. In Power Electronics and Drive Systems, 1997. Proceedings., 1997 International Conference on, volume 1, pages $53-58$ vol.1, may 1997.

[16] C.B. Jacobina, M.B. de R. Correa, R.L.A. Ribeiro, T.M. Oliveira, E.R.C. da Silva, and A.M.N. Lima. Ac/ac converters with a reduced number of switches. In Industry Applications Conference, 2001. Thirty-Sixth IAS Annual Meeting. Conference Record of the 2001 IEEE, volume 3, pages $1755-1762$ vol.3, september 2001.

[17] A. Dell'Aquila, A. Lecci, and M. Liserre. A technique to balance a half-bridge single-phase active filter. Industrial Electronics, 2003. ISIE '03. 2003 IEEE International Symposium on, 2(3):787 - 792, march 2003.

[18] A. Nasiri, S. B. Bekiarov, and A. Emadi. Reduced parts single-phase series-parallel ups systems with active filter capabilities. Telecommunications Energy Conference, 2003. INTELEC '03. The 25th International, pages 366 $-372,2003$.

[19] M.K. Hamzah, A.F.A. Ghafar, and M.N.M. Hussain. Single-phase half-bridge shunt active power filter employing fuzzy logic control. In Power Electronics Specialists Conference, 2008. PESC 2008. IEEE, pages $552-558$, june 2008.

[20] W. R. N. Santos, E. R. C. da Silva, C. B. Jacobina, A. C. Oliveira, and P. M. Santos. New configurations of single-phase universal active power filters with reduced number of electric power switches. In Energy Conversion Congress and Exposition (ECCE), 2012 IEEE, pages 1032-1039, 2012.

[21] B. Han, B. Bae, S. Baek, and G. Jang. New configuration of upqc for medium-voltage application. IEEE Transactions on Power Delivery, 21(3):1438 1444, july 2006.

[22] Z. Yin and L. Zhou. A novel harmonics injecting approach on over saturation suppression of dvr series injection transformer. In Power Engineering Conference, 2005. IPEC 2005. The 7th International, pages $1-498$, december 2005.

[23] C. B. Jacobina, I. S. de Freitas, E. R. C. da Silva, A. M. N. Lima, and T. M. de Oliveira. Ac-ac single-phase to single-phase two-legs converter. IEEE-IAS Annual Meeting, pages 2388-2394, 2005.

[24] C.B. Jacobina and T.M. Oliveira. Six-switch singlephase ac/ac converter. In Applied Power Electronics Conference and Exposition, 2001. APEC 2001. Sixteenth Annual IEEE, volume 1, pages 186-192 vol.1, 2001.

[25] C. B. Jacobina, M. B. R. Correia, T. M. Oliveira, A. M. N. Lima, and E. R. C. da Silva and. Current control of umbalanced electrical systems. IEEE-IAS Annual Meeting, pages 1011-1017, 1999.

\section{BIOGRAPHIES}

Welflen R. N. Santos was born in São Luís, Brazil, in 1979. He received the B.S. degree in electrical engineering from Centro Federal de Educação Tecnológica do Maranhão, São Luís, Brazil, in 2004, M.Sc. and Ph.D. degrees in electrical engineering from the Federal University of Campina Grande, Campina Grande, Brazil, in 2006, and 2010, respectively. Since July 2010, he has been with the Coordination of Electrical Engineering, Federal University of Piauí, Teresina, where he is now Professor of Electrical Engineering Course. His research interests include power electronics, power systems, control systems, industrial automation and electrical drives.

Edison R. C. da Silva was born in Pelotas, Brazil, in 1942. He received the B.C.E.E. degree from the Polytechnic School of Pernambuco, Recife, Brazil, in 1965, the M.S.E.E. degree from the University of Rio de Janeiro, Rio de Janeiro, Brazil, in 1968, and the Dr. Eng. degree from the University Paul Sabatier, Toulouse, France, in 1972. From 1967 to March 2002, he was with the Electrical Engineering Department, Federal University of Paraíba, Campina Grande, Brazil. Since April 2002, he has been with the Electrical Engineering Department, Federal University of Campina Grande, Campina Grande, where he is a Professor of electrical engineering and the Director of the Research Laboratory on Industrial Electronics and Machine Drives. In 1990, he was a Visiting Professor at the Alberto Luiz Coimbra Institute and Graduate School of Research and Engineering (COPPE), Federal University of Rio de Janeiro, Rio de Janeiro. From 1990 to 1991, he was a Visiting Professor with Wisconsin Electric Machines and Power Electronics Consortium, University of Wisconsin, Madison. Dr. da Silva is Fellow member of the Institute of Electrical and Electronics Engineers (IEEE) since 2003. His current research work is in the area of power electronics and motor drives. Dr. da Silva was the General Chairman of the 1984 Joint Brazilian and Latin-American Conference on Automatic Control, sponsored by the Brazilian Automatic Control Society, and was the General Chairman of the IEEE Power Electronics Specialists Conference (PESC) in 2005.

Cursino B. Jacobina was born in Correntes, Brazil, in 1955. He received the B.S. degree in electrical engineering 
from the Federal University of Paraíba, Campina Grande, Brazil, in 1978, and the Diplôme d'Etudes Approfondies and the Ph.D. degrees from the Institut National Polytechnique de Toulouse, Toulouse, France, 1980 and 1983, respectively. From 1978 to March 2002, he was with the Electrical Engineering Department, Federal University of Paraíba. Since April 2002, he has been with the Electrical Engineering Department, Federal University of Campina Grande, Campina Grande, where he is currently a Professor of electrical engineering. Dr. Jacobina is Fellow member of the Institute of Electrical and Electronics Engineers (IEEE) since 2013. His research interests include electrical drives, power electronics, and energy systems.

Eisenhawer de M. Fernandes was born in Campina Grande, Paraíba, Brazil, in 1981. He received the B.S., M.Sc. and Ph.D. degrees in electrical engineering from the Federal University of Campina Grande (UFCG), Campina Grande, Brazil, in 2004, 2006 and 2011, respectively. From September 2006 to April 2008, he was with the Department of Electrical Engineering of the Federal University of Vale do São Francisco (Univasf). Since May 2008, he is with the Department of Mechanical Engineering of the Federal University of Campina Grande (UFCG), Campina Grande, Brazil. In 2013, he was Visiting Professor at the Wempec research group of the University of WisconsinMadison, Madison, U.S.A., working on project of self-sensing control of permanent-magnet synchronous motors (PMSM). Dr. Fernandes is member of SOBRAEP and SBA societies since 2012. His research interests include electrical drives, power electronics and control systems.

Alexandre C. Oliveira was born in Fortaleza, Brazil, in 1970. He received the B.S., M.Sc., and Ph.D. degrees in electrical engineering from the Federal University of Paraíba, Campina Grande, Brazil, in 1993, 1995, and 2003, respectively. From 1996 to 2004, he has been a faculty member with the Department of Electrical Engineering, Centro Federal de Educação Tecnológica of Maranhão, Brazil. Since November 2004, he has been with the Department of Electrical Engineering, Federal University of Campina Grande, Campina Grande, where he is currently an Associate Professor of electrical engineering. His research interests include electrical drives, power electronics, and control systems.

Rafael R. Matias was born in Campina Grande, Brazil, in 1982. He received the B.S. degree in electrical engineering from Federal University of Paraíba, in 2005, M.Sc. and Ph.D. degrees in electrical engineering from the Federal University of Campina Grande in 2007 and 2012, respectively. Since January 2010, he has been with the Coordination of Electrical Engineering, Federal University of Piauí, Teresina, where he is now Professor of Electrical Engineering Course. His research interests include industrial electronics and electrical drives.

Dalton F. G. Filho was born in Corrente, Piauí, Brazil, in 1980. He received the B.S. and M.Sc. degree in Electrical Engineering from Federal University of Campina Grande(UFCG), Campina Grande, Paraíba, Brazil, in 2007, and 2012, respectively. The B.S. was in cooperation with the National Polytechnic Institute of Grenoble - INPG/France.
Since 2008 he works in São Francisco's Hydroelectric Company - CHESF, Recife, Brazil with planning and designing of systems for power transmission in high and extra high voltage. His research interests include power electronics, transmission systems and FACTS.

Otacilio M. Almeida received the B.S. degree in Electrical Engineering from the Federal University of Ceará, Fortaleza, Brazil in 1987, the M.Sc. degree in Electrical Engineering from the State University of Campinas, Campinas, Brazil in 1998, and the Ph.D. degree in Electrical Engineering from the Federal University of Santa Catarina, Florianópolis, Brazil in 2005. He has been a professor with the Federal University of Ceará since 1991. His research areas are electric machinery, electrical machine drives, advanced control techniques for electromechanical systems, and nonlinear systems.

Patryckson M. Santos was born in São Luís, Brazil, in 1981. He received the B.S. degree in industrial electrical engineering from Federal Center of Technological Education of Maranhão, São Luís, Brazil, in 2004, and M.Sc. degree from Federal University of Campina Grande, Campina Grande, Brazil, in 2006. From 2006 to 2007, he was with the Department of Electrical Engineering of the Federal University of Vale do São Francisco (Univasf). Since 2007, he was been with the Electrical Engineering Department, Federal University of Maranhão, São Luís, where he is currently a Professor of electrical engineering. His research interest include electrical and machines drives, power electronics, energy systems, industrial automation and intelligent systems. 